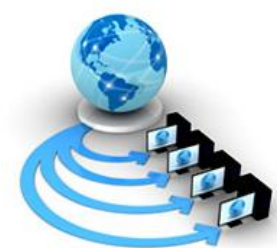

\title{
DEVELOPMENT OF AN ONLINE INTEGRATED STUDENT MANAGEMENT INFORMATION SYSTEM: CASE STUDY "UNIVERSITY OF GITWE"
}

\author{
Dr. Gatete Marcel \\ Lecturer, University of Gitwe \\ Ruhango District, Southern Province, Rwanda, Africa \\ Dr. Uwizeyimana Faustin \\ Lecturer, University of Gitwe, \\ Ruhango District, Southern Province, Rwanda, Africa.
}

\begin{abstract}
Most of higher learning institutions currently adopt manual systems to manage their students' records. This results in putting pressure on people to be correct in all details of their work at all times, which sometimes is not possible. With manual student management systems, the service level is always dependent on individuals and this puts a requirement on management to run training continuously for staff to keep them motivated and ensure they are following the correct procedures. It can be very easy to accidentally end up with inconsistency in student data entry operations and even in hand-written student recording registers; this degrades the quality of services provided to the students. To provide a permanent solution to those problems, we designed a student information management system that provides a simple and effective way of managing student information. The main objective of UGSMIS (University of Gitwe Student Management Information System) is to allow registrar retrieve the details of students, course details, curriculum,instructor, student grades to track student information and manage student-related data. Users (registrar/assistant and administrator) can generate semester grade reports and student transcript at the end of graduation, batch details, placement details, and other resource-related details too. With GSMIS, students can register themselves, edit their personal data, receive details about their academic progress, and retrieve reports, any other assignment details, and final exam results. GSMIS is a secure, beautiful online interface embedded in the University of Gitwe's website. It provides faculty details, batch execution details, students' details in all aspects, the various academic notifications to the staff and students updated by the university administration. It also facilitatesusexplore all the activities happening in the university,different reports and queries can be generated based on vast options related to students, batch, course, faculty, exams, semesters, certification. The system was developed using technologies such as PHP, HTML, Jquery, JavaScript, CSS and MySQL.
\end{abstract}

Keywords: Automation, Information, PHP, MySQL Server, Professional Education.

\section{INTRODUCTION}

\section{I.1 Introduction}

A university/college system continuously generates and uses a large amount of data that has to be communicated appropriately to staff, students, faculty, and sometimes parents. Much of higher learning institutions currently use manual systems, they need a lot of time, competentmanpower, costly equipment and material are needed to manually perform single tasks. This often results in some information being lost during the transit from one service to another, space wastage, information flow problems, etc.

The implementation of an efficient student information management system is an effective way to get rid of the traditional student record-keeping system. Instead of dealing with manual files, the use of booth well-managed database and a proper front-end design would not only reduce the make the task of the registrar and his assistants in charge easier but also the operating cost [1][8].

This type of customizable automated application used to suit various users' needs as it helps a university or any other educational institution to store, manage, and distribute this information. It electronically stores students' details, lecturer, administrator, registrar, and department head [2][9].
The accuracy is maintained easily as the staff work is computerized and it is controlled managed and controlled by an administrator. He has to insert, update and monitor the whole process. He has to ensure the highest possible level of security by storing data on database servers [3].

UGSMIS (University of Gitwe Student Management Information System) automates the functioning of the University of Gitwe (UG)'s registrar office and accessible over the Internet. Register along with his assistant can to directly access all aspects of a student's academic progress through a secure, online interface embedded in the university's website. The system utilizes user authentication, displaying only information according to the right of the user, this authentication allows the authorized users to create or update information in that subsystem relevant to their duties.

The main use of this online application comes from its major advantages to staff and students of this university as previously it was not eager to find the information they were seeking. Itautomates all those basic tasks like keeping the record of all student details. Thus, this system reduces the manual work to a great extent by allowing smooth flow of the student activities and removing the chances of errors in the details.

\section{I.2 OBJECTIVES}

General Objective: 
- The main objective of this study was to develop an online application to automate the student management process by the registrar of the University of Gitwe.

\section{Specific Objective:}

- Design the database for storing student information using MySQL

- Provide a web-based application accessible to the university registrar, students, faculty, etc.

- Increase the effectiveness of university record management processes.

- To provide security to student data

- Reduce student records' access time along with their deliverance

- Decrease errors during the recording periods.

- Provide reports about student details.

The remaining part of this paper is organized as follows: A brief Statement of the Problem Definition with the Existing System is provided in Section II. In section III, the Proposed System is presented. The Methodology is discussed in Section IV while the results discussions are presented in Section V. Featured Case Study are provided in Section VI. We conclude our work in section VII.

\section{II.EXISTING SYSTEM}

The manual student recording system is cumbersome tedious, time-consuming, the mode of retrieving and storage of student registration is inadequate. It is always done manually by the registrar and his assistant.

Some of the problems are the following:

- It is time-consuming to record files

- Not efficient: When it comes to the question of searching records, this was a tedious task. One could be searching for thousands of records looking only for one record, it required the registrar o go through all records one by one.

- Delay in bringing documents to those who need them

- No system for properly transferring or removing of inactive files.

- Files get easily lost: Using the manual system, various files were lost which often results in the loss of thousands of records.

- Costly: Various files and other related items had to be regularly purchased for manually handling various registrar records.

- Space-consuming: The files storage was another challenge as they often occupied some unnecessary space in in the university

- Error-prone

- Difficulty to integrate data

- Data redundancy: They were the same copies of records spread throughout the university

- The manual system also required the use of inappropriate software such as word processing, spreadsheets, etc
- The difficulty of locating \& finding files dependent on each other.

- The damage of files: Files easily used to get damaged.

\section{THE PROPOSED SYSTEM}

The automated web-based student management system overcomes the previously mentioned problems associated with the manual system which was adopted by the University of Gitwe along with the key features mentioned in the following section:

\subsection{Basic requirements}

The basic requirements for this application is users (administrator, registrar, registrar-assistant, students, etc) which should have their own identities. The administrator is acting as the controller of the system and has all administrative privileges. The registrar/assistant has some advanced privileges to the system and can manage and maintain student records. The standard users are students who usually accessthis System and can register, update, view results, etc

\section{Functional requirements}

1. UGSMIS aims to improve the efficiency of university information management, and the main function is managing and maintaining student-related information.

2. The administrator, registrar/assistant, and students are the entities in functional requirements in the system. The Administrator is granted all privileges (enable/disable/ update), so it is ensured that the information entered is in the correct format. $\mathrm{He} / \mathrm{she}$ has the following duties:

- The system requires login before providing any function to the administrator.

- Control the overall activities in the system.

- Change his /her account information.

- Remove wrong entries from the system.

- View reports in different operations in the system.

3. Registrar has the following duties and permissions:

- The system shall require login before providing any function for the registrar.

- Change his /her account information.

- View the notice information

- Calculate the cumulative GPA for any student.

- Search any student detailed information, etc.

4. Students have the following permissions:

- The system shall authenticate them before accessing the system.

- Display Notice.

- View their academic status/grades.

- View the notice information.

- Display student's detail, etc.

\section{Non-Functional requirements}

\section{Performance requirements:}

The system administrator usually ensures that the performance is high, so, he performs various checkings on 
the working performance of the software by detecting problems which degrades the performance of the system, their causes, and applies various tools and techniques efficient in remedying such problems [4].

\section{Safety Requirements:}

Database backup is the process of backing up the operational state, architecture and stored data

To avoid the prompt database and system crash and data loss at a certain time due to virus or operating system failure, or any other operating problems, it is required to regularly back up the operational state, architecture and stored data of database software [5][10].

\section{Security Requirements:}

- For security reasons, many appropriate layers and types of information security controls are currently available to system administratornamelyAccess control, Auditing, Authentication, Encryption, Integrity controls, and Backups, etc. The system administrator regularly ensures that those controls are applied [6].

\subsection{Development Tools}

- Programming Language: PHP 7

- Server: APACHE HTTP Server

- Front-End: HTML and JavaScript, CSS, jquery

- Back-End: MySQL

- Operating System: Microsoft Windows or Linux

- The client of PC may use one of the following browsers:

\section{- Internet Explorer}

- Mozilla Firefox

- Google Chrome, etc...

\subsection{Interface}

The advantage of the user interface of the new system is that it is platform-independent i.e. it is accessible online with any Internet and browser-equipped devices.

\subsection{Devices}

The application is currently accessed by using computers. The system is designed with advanced technology to run on small handhelds such as tablets and mobile phones using any of the above-mentioned Internet web-browsers.

\subsection{Hardware Required}

\section{LEVEL 1- REGISTRAR}

- Processor: Intel Pentium IV processor or equivalent or higher

- RAM: 1 GB RAM or Higher

- Disk: 20 GB HDD or Higher

- Connectivity: Internet Connectivity.

\subsection{System Design}

The working process of the UGSMS is shown in the following diagrams: The data flow diagram provides a graphical representation of the flow of student's information from the registration process till the end of his/her course. This flow diagram depicts also the visualization of data processing.

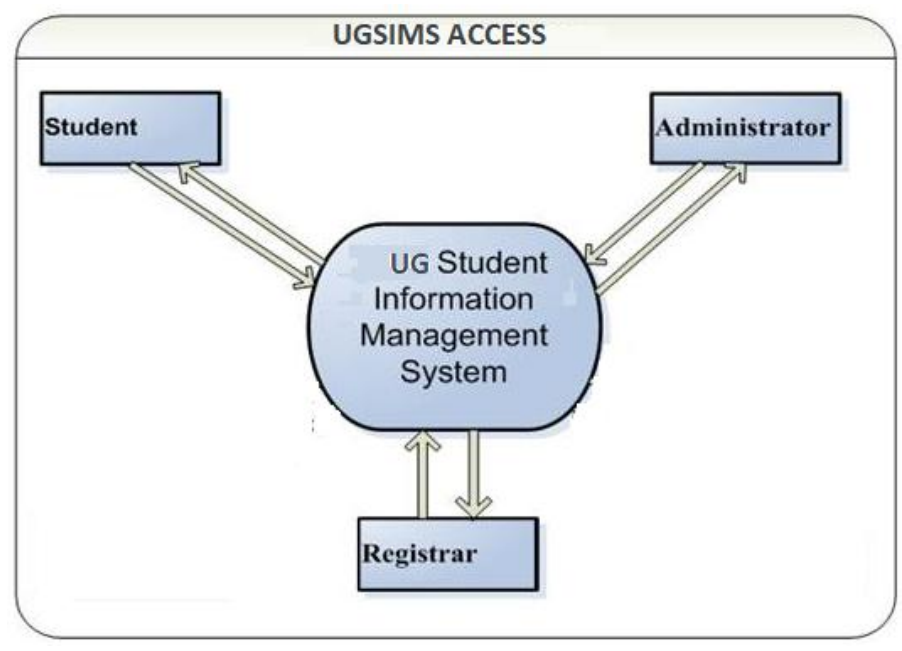

Figure 1.The UGSIMS Access

\section{LEVEL 1- ADMIN}

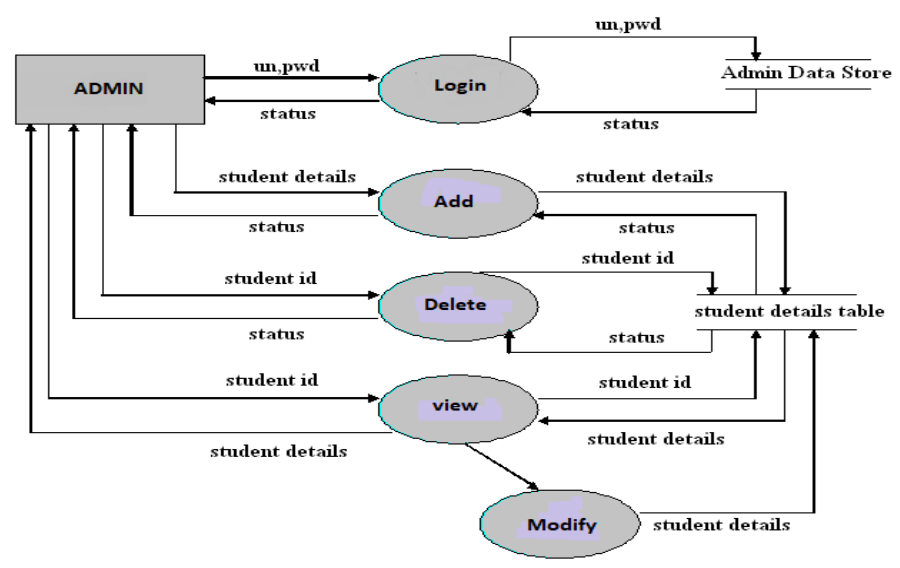

Figure 2. UGSIMS Use Case Diagrams-Administrator 


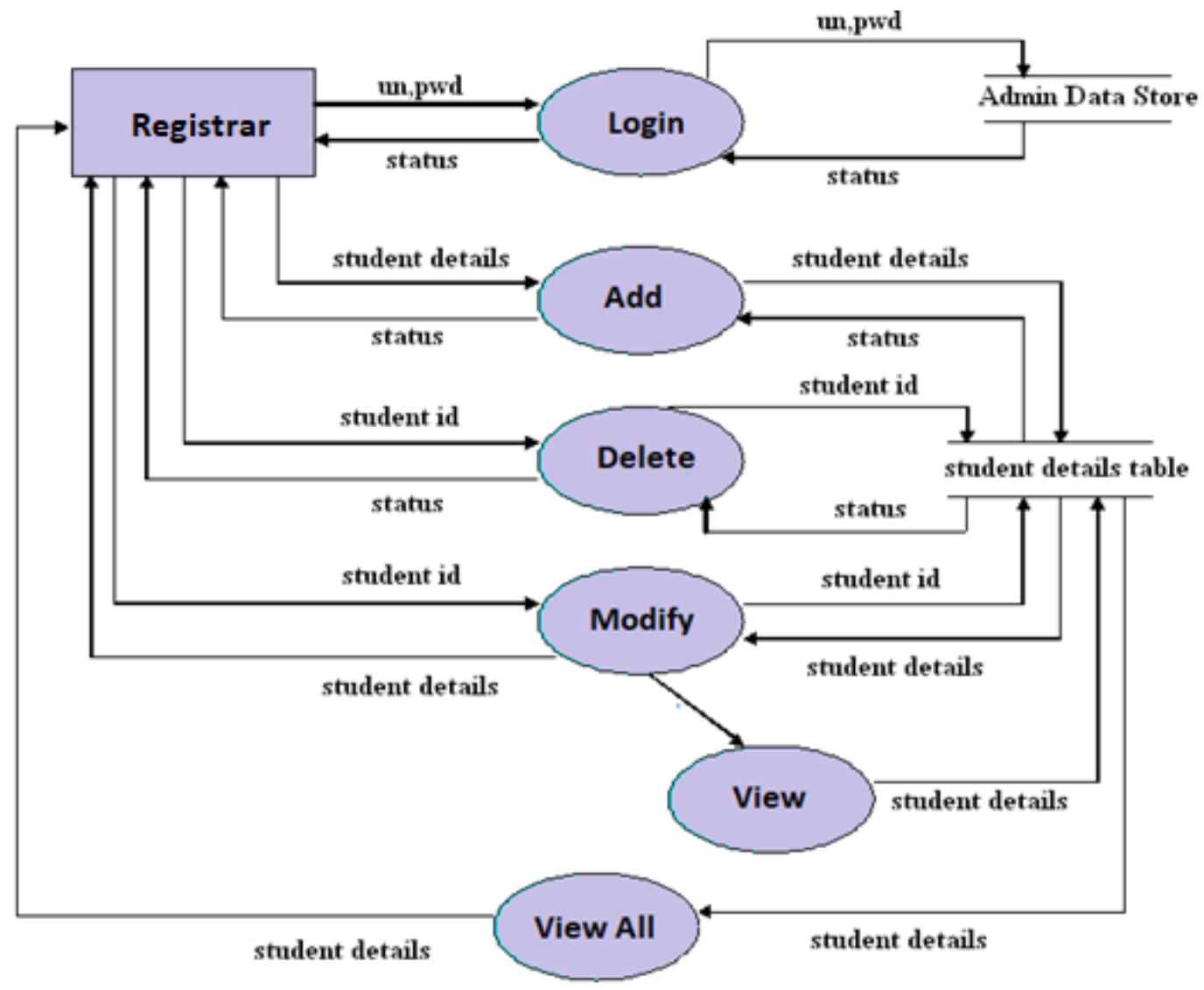

Figure 3. UGSIMS Use Case Diagrams-Registrar

\section{LEVEL 1-STUDENT}

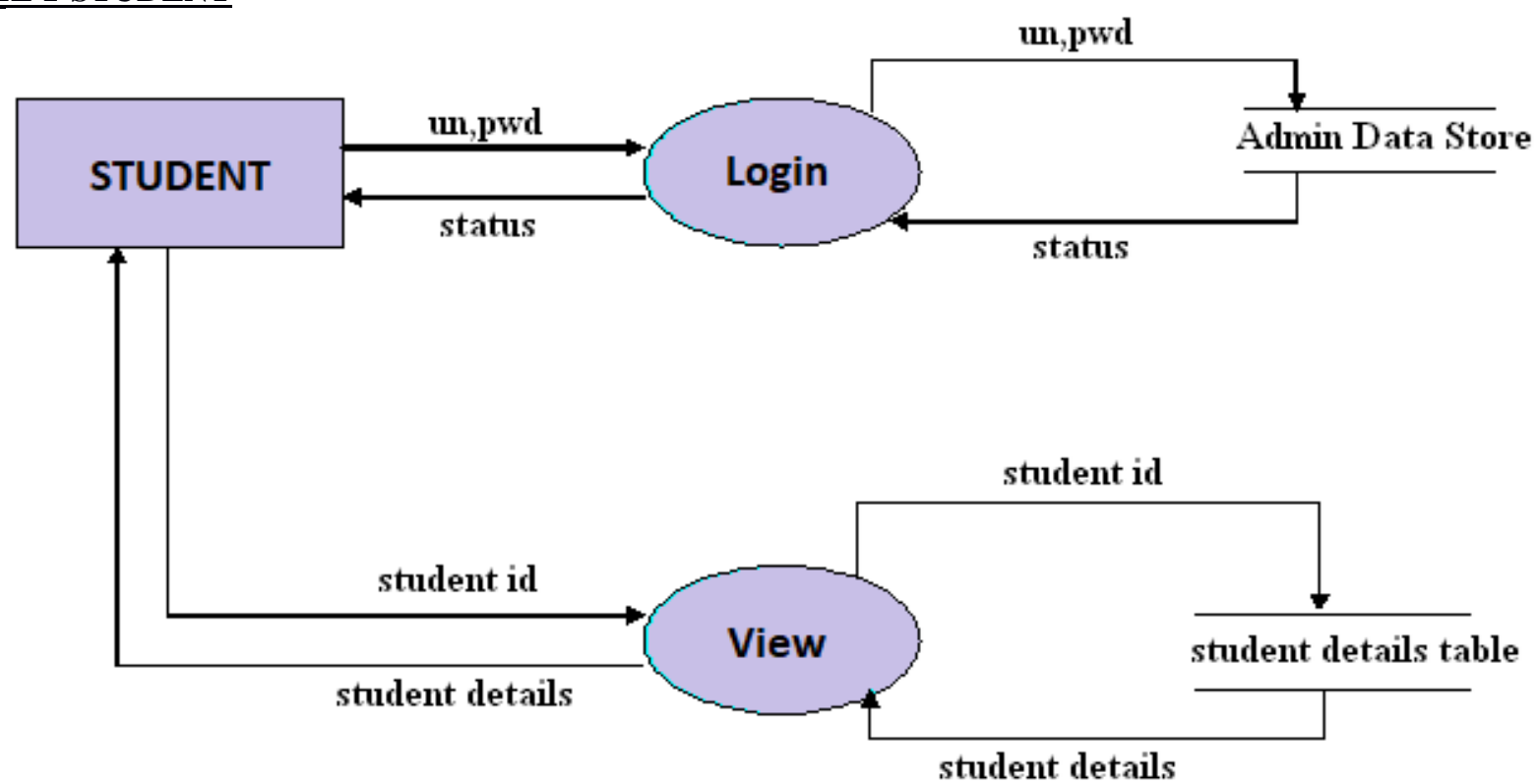

Figure 4. UGSIMS Use Case Diagrams-Students

\subsection{Modules}

\section{Registration Module}

This module comprises all processes related to the administrator, registrar/assistant, and student registration operations. Admin is the administrator of the system, he/she can add or remove other users and anything to and from the system respectively. Students and staff (Register/assistant) have to register themselves into the system to create their accounts.

2. Logins

After successful registration, users can then login to the system by entering code numbers sent to their respective emails along with their e-mail ids and passwords.

\section{Search Options}

Both Admin and Student/staff can search for information aboutstudents by year of registration and by course. The system provides different types of search: 
$\checkmark$ Detailed: This displays all students of related courses during such academic year and information related to eachstudent.

$\checkmark$ Condensed search: This displays summarized notes ofall students data of such academic year; displayed are first name, last name, e-mail id on a single page; there are navigation options page by page through the whole list.

\section{Admissions}

Registrar/assistant can generate the admission number for students, or reject his/her application.

\section{Student information management}

Registrar/assistant can perform the following operations:

$\checkmark$ View pending applications, provisionally selected list, rejected lists, final lists

$\checkmark \quad$ Send and receive e-mails to/from students and view them

$\checkmark$ View answered req-messages, searching particular student's data and edit them

$\checkmark$ Perform self-assessment verification, generate and print detailed and mini-reports,

$\checkmark$ Register new students per semester and update the data

$\checkmark$ Upload students' documents,

$\checkmark$ Generate registration numbers, etc.

\section{Reporting}

With the new proposed system, the registrar/assistant can to generate various detailed and mini-reports relating to student data.

\section{METHODOLOGY}

UGSMIS is based on the database, object-oriented programming language, and networking techniques [7]. This system uses PHP as the front-end software which is an object-oriented programming technique and has connectivity with MySQL, the back-end software, and some advanced client-side technologies.

\section{RESULTS AND DISCUSSION}

As seen in the following figures, this research study shows that all user expectations were fully supported as UGSIMS meets user requirements relating to registering new users (registrar, registrar-assistant, students), displaying users and student information, student information management, reporting, etc. The provided figures are simply samples as the system itself computerizes the management everything about students in the whole university.

\subsection{UGSIMS Website Welcome Screens}

As shown in Fig. 3, Fig. 4, and Fig. 5, welcome screens are initially displayed to the user which contains useful information about the university such as its mission, past, current and future events in the institution.
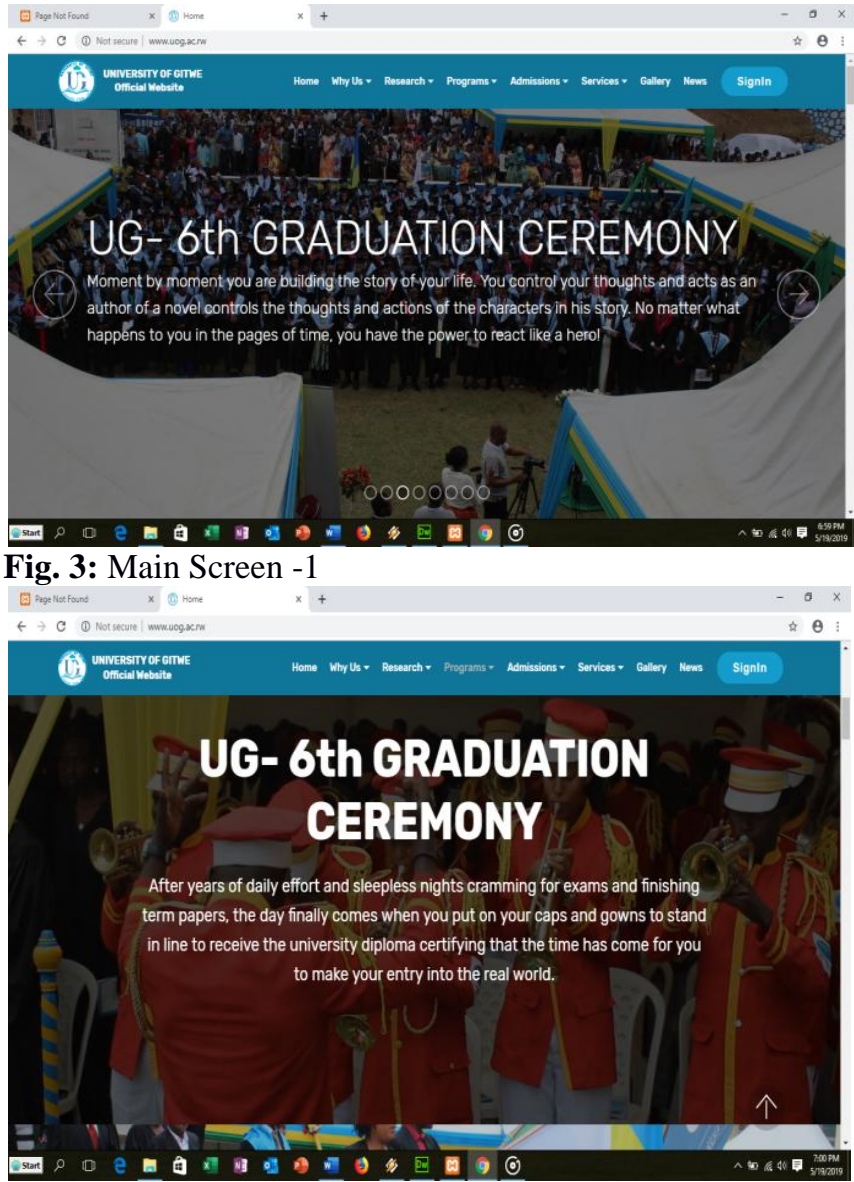

Fig. 4: Main Screen -2

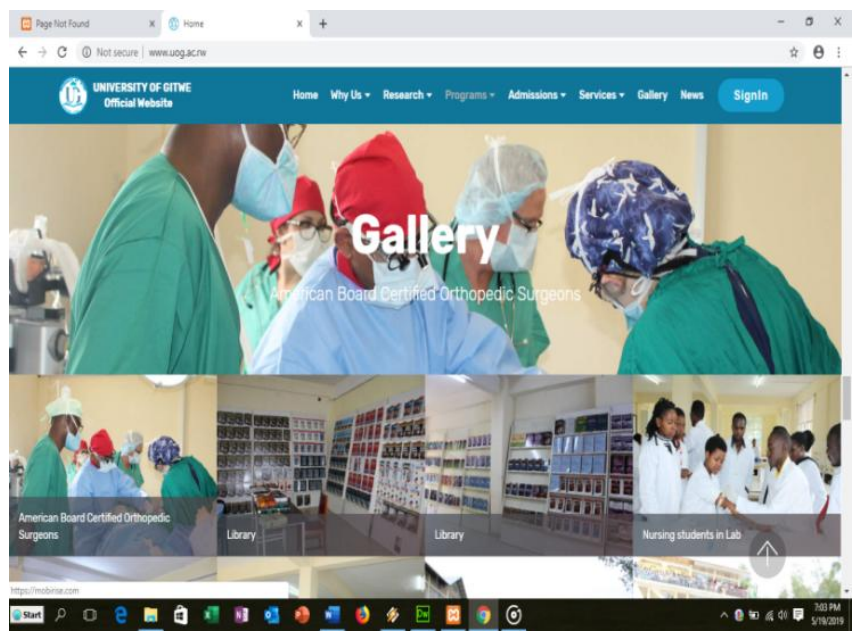

Fig. 5: Main Screen -4

\subsection{UGSIMS ACCESS AND DIFFERENT TYPES OF SEARCH}

\subsubsection{Login to the Registrar Section}




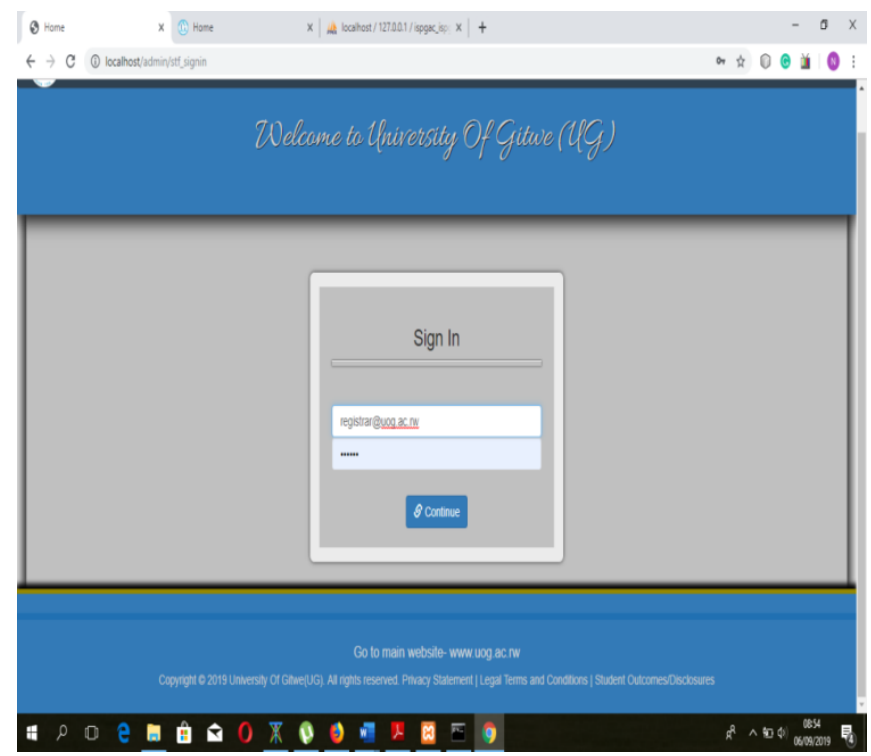

Fig. 6: Registrar Login Screen

As seen in Fig.6, Register and his/her assistant can login to the system using their e-mail address and their passwords, a message containing an activation code is sent to their phone and e-mail address, before hitting Continue button.

\subsubsection{Different Types of Search}

\section{A. General Search}

After successful login, the registrar and his assistant are redirected to a welcome screen (Fig. 7 and Fig. 8) where they can perform various types of search i.e. detailed and condensed. A detailed search provides details about each student information while condensed provided an overview of student's information.

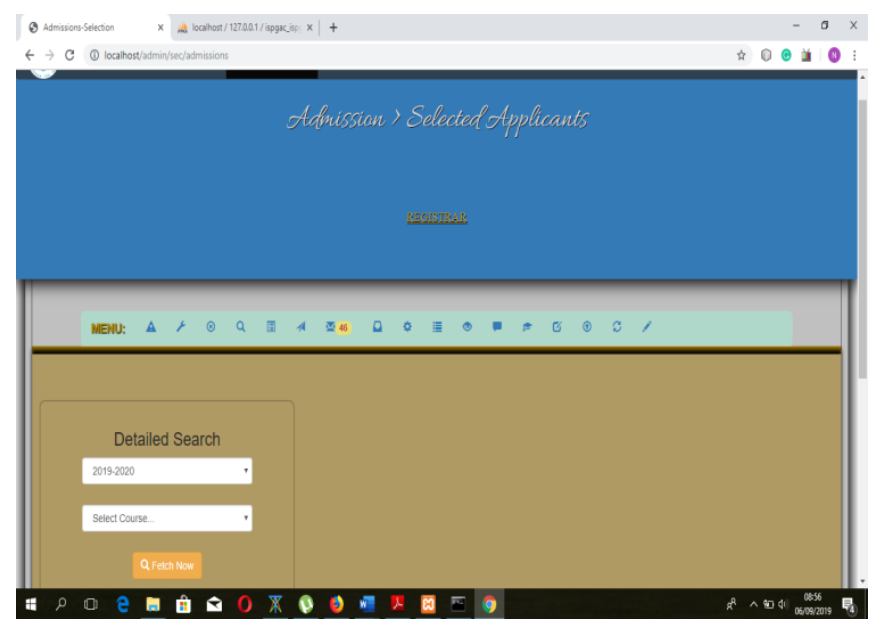

Fig. 7: First Login

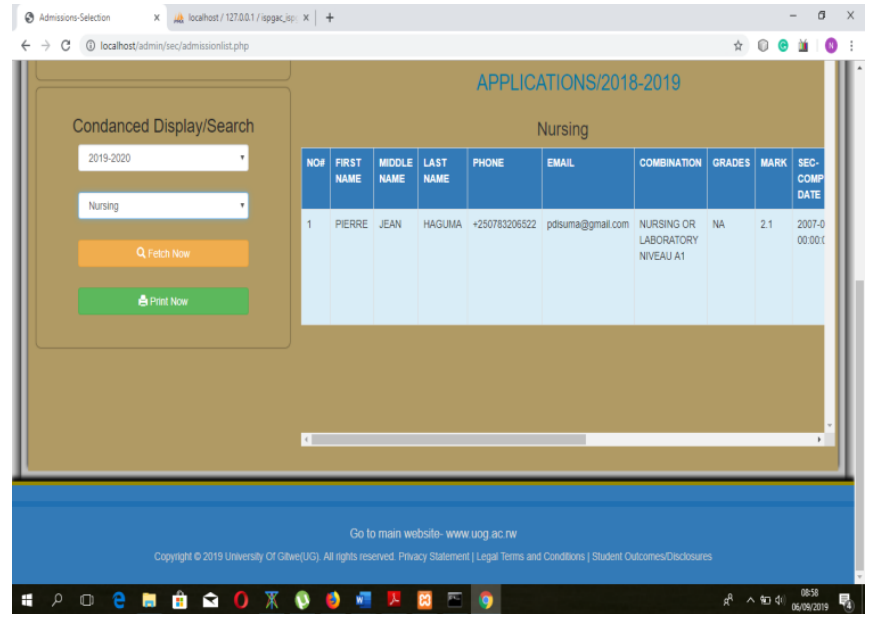

Fig. 8: Pending student applications

\section{B. Displaying admitted Students}

Fig. 9 depicts a situation where the Register and his/her assistant display all students provisionally admitted to the university. These students are displayed using condensed display/search by faculty, academic year, and selection category.

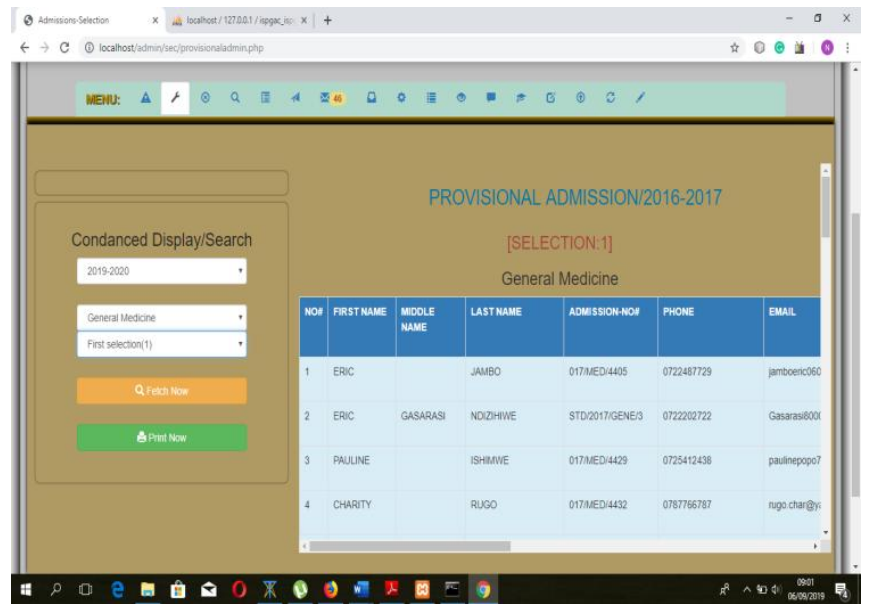

Fig. 9: Provisional Admission

\section{Displaying rejected Students}

Fig. 10 depicts a situation where the Register and his/her assistant display all student whose admission has been rejected from the university. These students are displayed using condensed Display/search by Faculty, academic year, and selection category. 


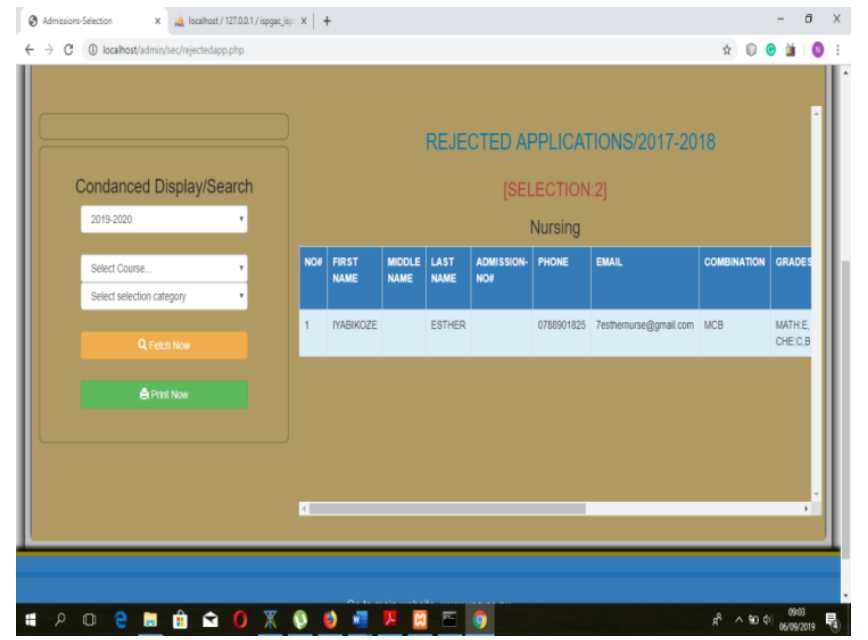

Fig. 10: Rejected List

\section{Advanced Search}

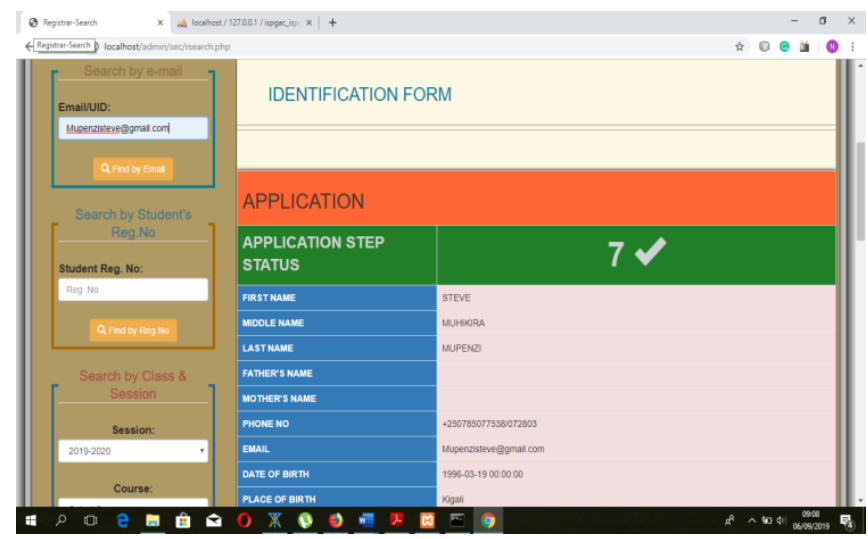

Fig. 11: advanced Search criteria

As seen in Fig. 11, an advanced search criterion is used where the registrar can use search using student's e-mail address and register number, search by class, session, and course. This kind of search displays information student by student along with their application progress status.

\section{E.Displaying Final List}

Fig 12 and Fig. 13depicts the criteria used to display the final list of selected students. This type of search is performed using criteria such as session, course, level/class, semester, and class. This search can be also done using a condensed search where we can display condensed list of selected students. Registrar/assistant can send messages to this group of students informing them about their selection status.

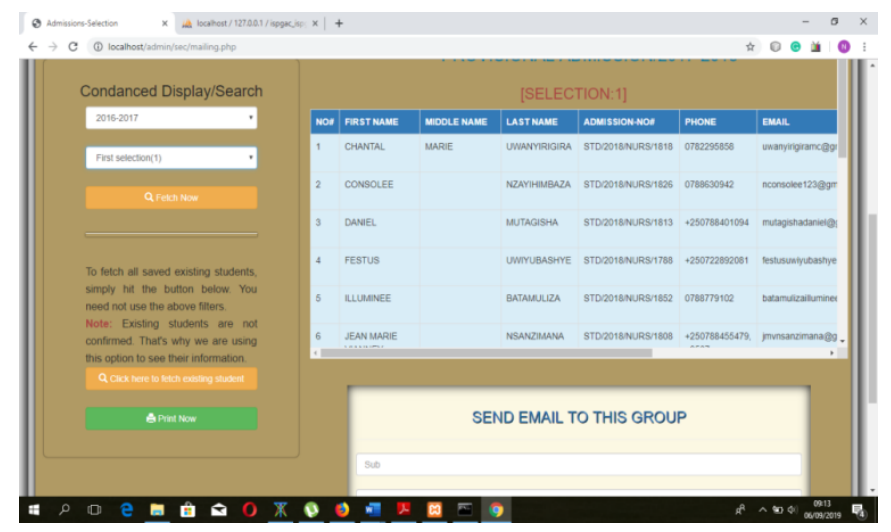

Fig. 12: Final List

\section{F. Displaying Received E-mails}

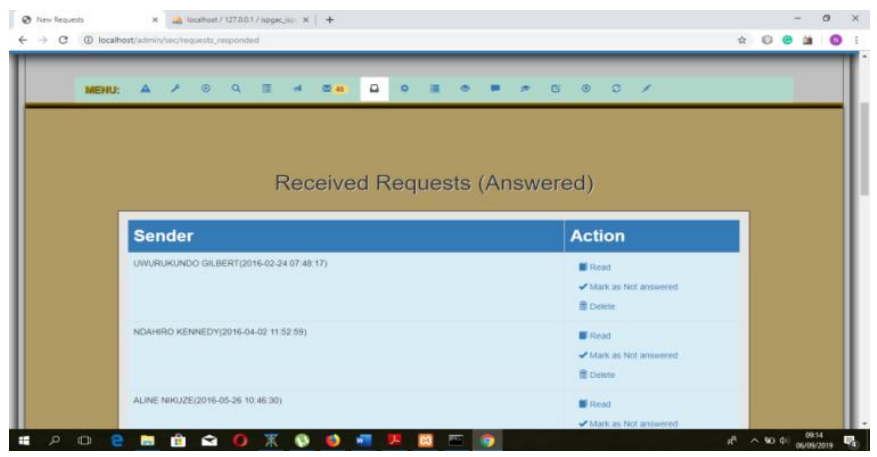

Fig. 13: Received E-mails

In UG-SMS, students can send e-mail messages to the register, he has the option to read messages, mark them as not answered, delete them, etc. (Fig. 13)

\subsection{Editing Student Basic Information}

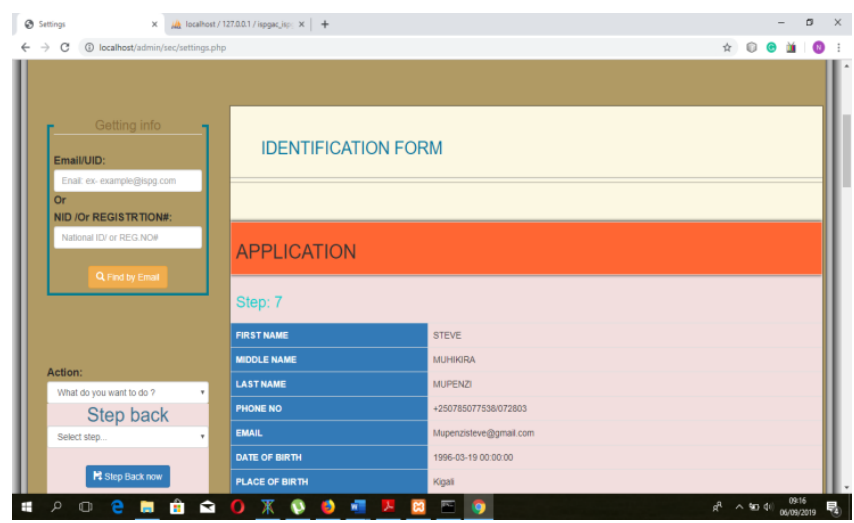

Fig. 14. Student Information

Registrar can retrieve the student information using their emails, National IDs, and registration numbers, this displays the student identification form and current admission status(Fig. 14). In Fig. 15, he/she can edit student information, to do he/she has to first display student basic information using one of the searches previously mentioned.

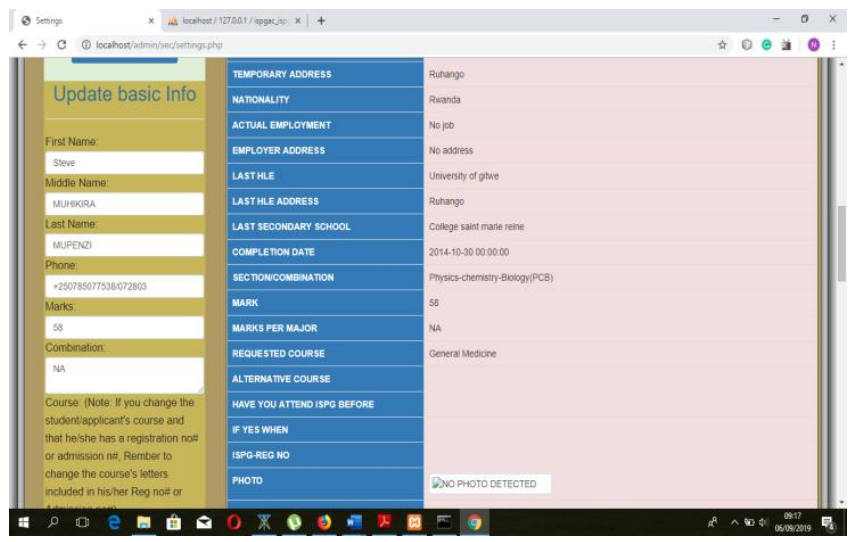

Fig. 15: Editing student's basic Information

\subsection{Deleting Student Account}




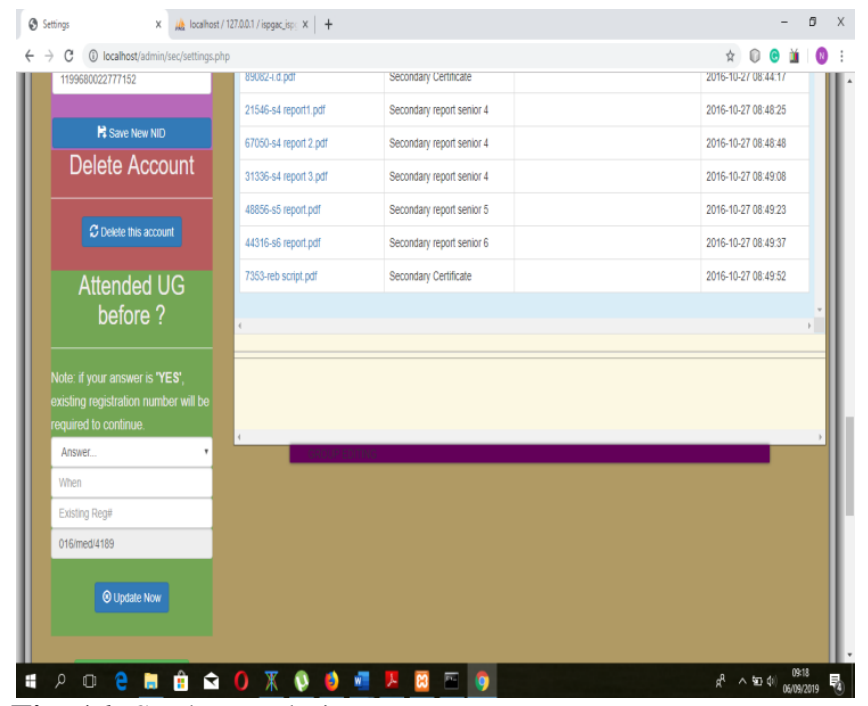

Fig. 16: Student Deletion

As shown inFig. 16,theregistrar can delete student's data along with his/her account information. These are permanently deleted no backup is possible.

\subsection{Reporting}

As seen in Fig. 17and Fig. 18, Registrar and his/her assistant can generate various reports namely condensed and detailed, print the same using different criteria such only selected, admitted, rejected, etc. by session, level, course, and semester, etc.

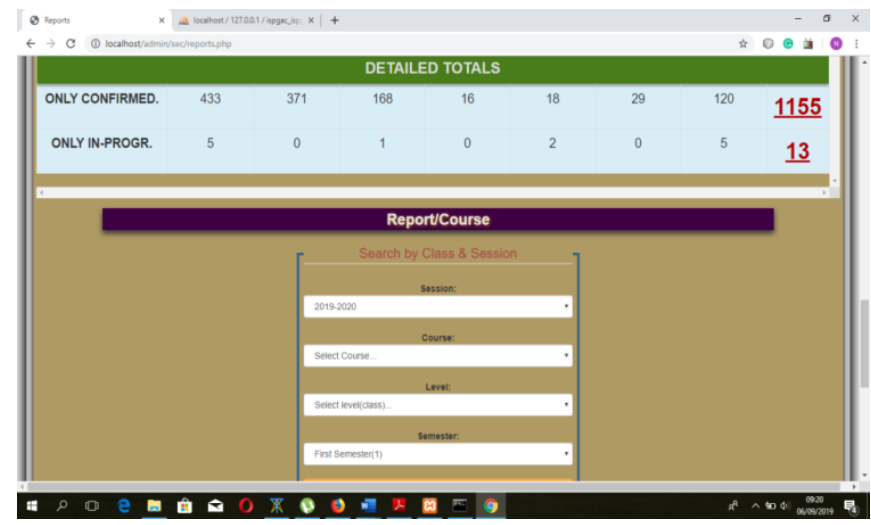

Fig. 17: Detailed Report

]
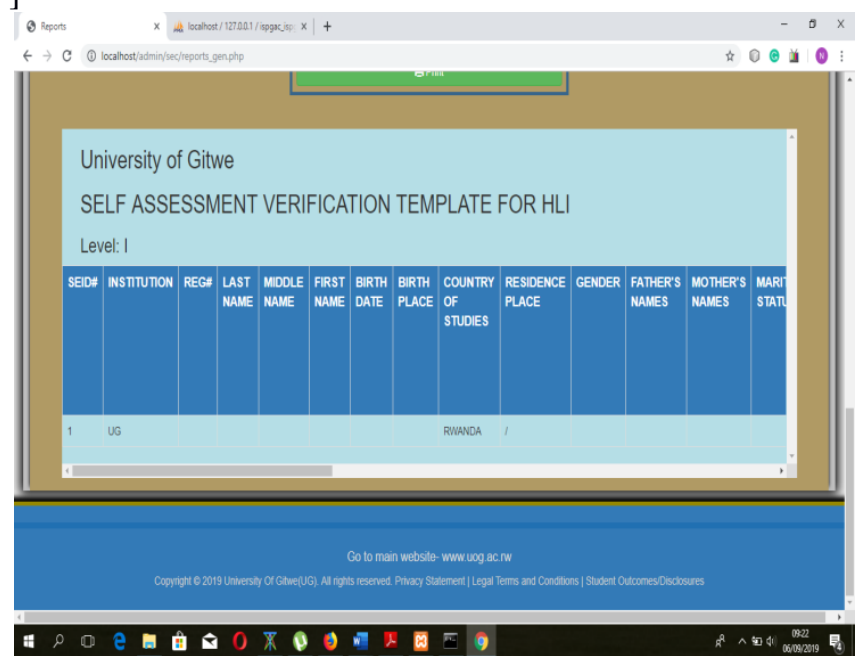

Fig. 18: Condensed Report
5.6 Student Panel for particular Semester Registration In addition to the first fresh student registration, students have to register for each new particular semester. This is done on the panel like the one displayed in Fig. 19. He/she has to identify him/herself and mention she is a new or existing student and then enter his/her respective registration number. If she/he is a new student, she/she is then redirected to the new students' registration page otherwise he/she hastoregister him/herself for the new particular semester (Fig. 20).

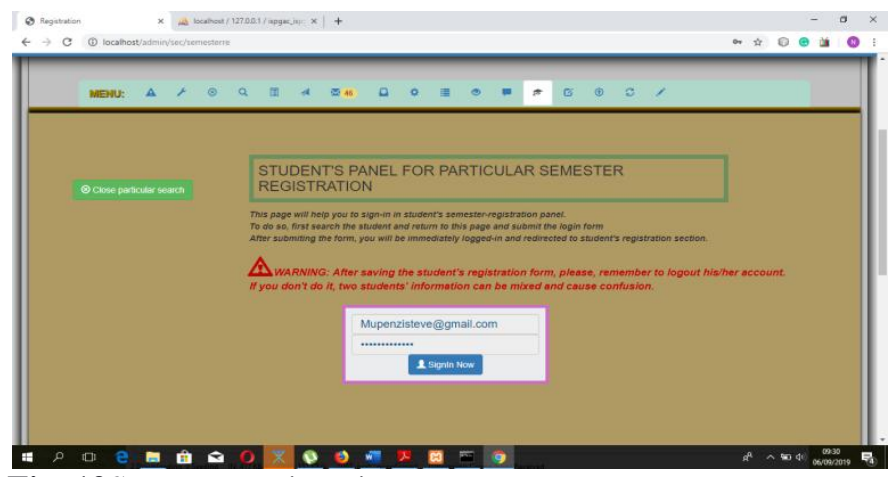

Fig. 19Semester registration

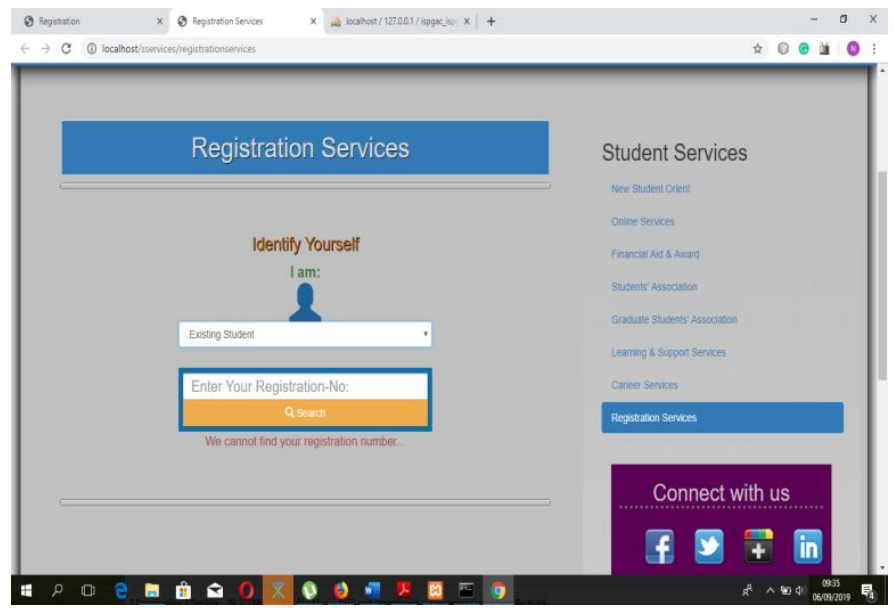

Fig. 20: Login for Semester Registration

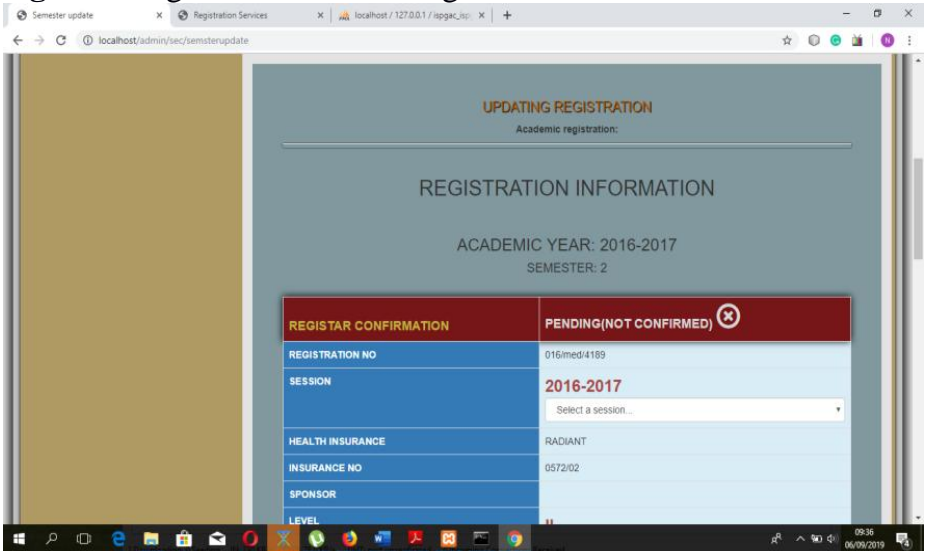

Fig. 21: Editing student registration

In Fig. 21, Registrar/assistant can edit student registration and validate the same by confirmation. He/she can change the registration session, etc. for the same student 


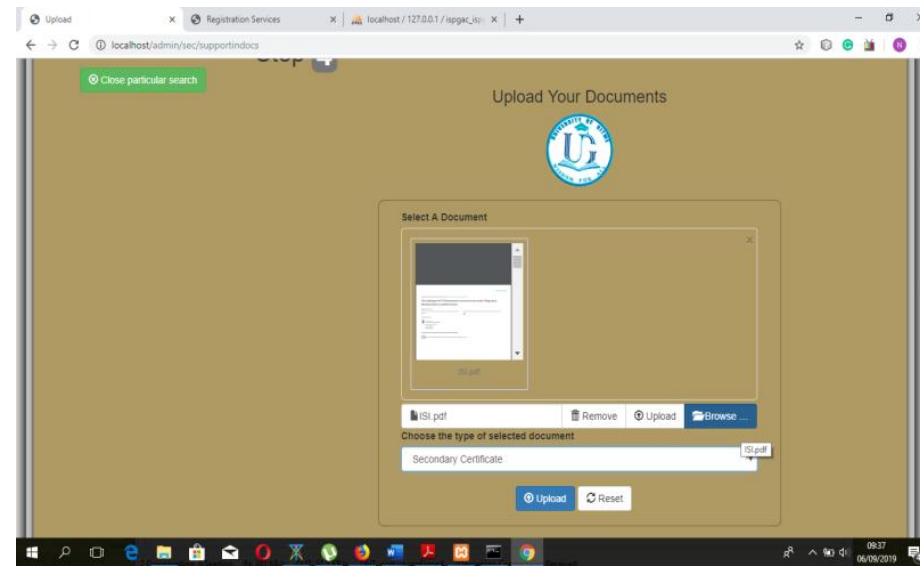

Fig. 22: Document upload

As seen in Fig. 22, upon a successful semester registration, after the registrar's confirmation for a particular student, he/she can upload various academic documents to his/her account.

\subsection{Generating Registration Number for students}

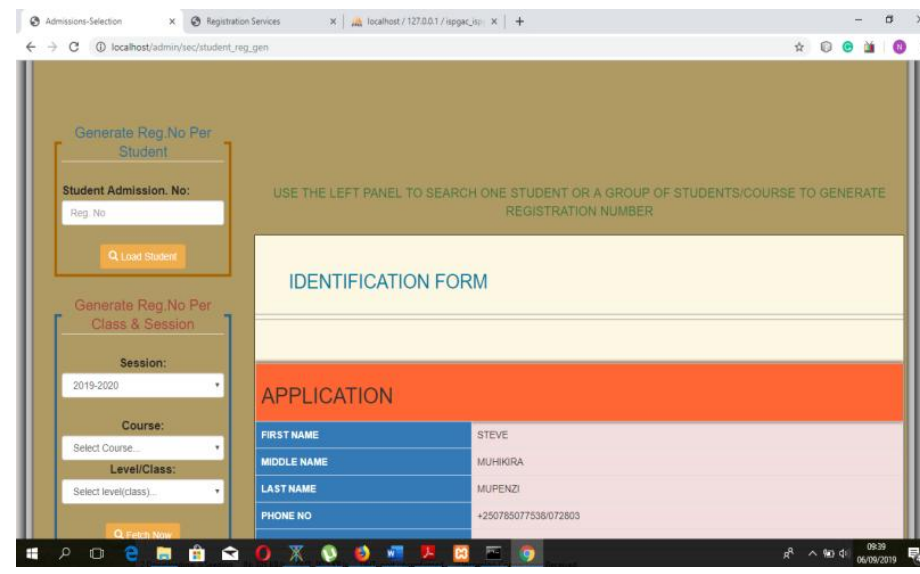

Fig. 23. Registration no. Generator

In Fig. 23, one can see that Registrar can generate registration number to various students this is done after searching for a particular student or a group of students and generate their respective register numbers.

\section{FEATURED CASE STUDY}

UGSIMS is currently available online as a sub-module of University of Gitwe Integrated Management Information System (UGIMIS) website with:

- 100 Visitors per day

- 1600 Users (Students)

- 150 Users (Staff)

- $24 / 7$ online, data availability to student/staff

- Automation of processes: All

- $30 \%$ of operational cost reduction

- $100 \%$ reduction in paperwork

- $90 \%$ improvement in patron care
- $90 \%$ reduction in information flow-time

- Enhanced competitive advantages

- $100 \%$ timely \& accurate information

- $100 \%$ of student/staff/guests delights, etc.

\section{CONCLUSION}

The developed UGSIMS facilitates the various activities taking place at the University of Gitwe. This system is essential for the staff to decrease their workload, so malpractice is reduced. It is equippedwitha secured, digitalized, and user-friendly interface. Operations that were manually maintained have been computerized, and are currently accessible online 24/7. Thus the new system which is a highly efficient GUI-based component is currently working properly and meeting all user requirements. It was created to overcome the problems effectively without any corrupted data or information.

\section{REFERENCE}

[1] H. Schildt, "Java ${ }^{\mathrm{TM}}$ : The complete reference," 9 th Edition, Oracle Press, 2015, ISBN: 978-0-07-180856-9.

[2] Zhibing Liu, H.W., HuiZan, "Design and implementation of student information management system", International symposium on intelligence information processing and trusted computing, 2010.

[3] Zhi-gang YUE, You-wei JIN, "The development and design of the student management system based on the network environment",2010 International Conference on Multimedia Communications, 978-0-7695-4136-5/10 2010 IEEE.

[4] Berners-Lee, T. J. 1992. "World-Wide Web: Information Universe", Electronic: Research", Applications and Policy.www.w3.org/People/Berners-Lee/Longer.html [accessed on 24th May 2011].

[5] R. Salman, "Developing Multithreaded Database Application Using Java Tools and Oracle Database Management System in Intranet Environment," International Conference on Advanced Information Technologies and Applications, pp. 67-79, 2015.

[6] J. M. Hellerstein, M. Stonebraker, J. Hamilton, "Architecture of a Database System," Journal Foundations and Trends in Databases, USA, Vol 1, Issue 2, pp 141-259, 2007.

[7] Rumbaugh, J., Jacobson, I., \&Booch, G., "The Unified Modeling Language Reference Manual: the definitive reference to the UML from the original designers", Singapore: Pearson Education Inc., 2003.

[8] Zhibing Liu, HuixiaWang,HuiZan "Design and implementation of student information management system.", International symposium on intelligence information processing and trusted computing. 978-0-76954196-9/10 IEEE, 2000.

[9] Jin Mei-shan1 Qiu Chang-li 2 Li Jing 3. "The Designment of student information management system based on B/S architecture", 978-1-4577-1415-3/12 2012 IEEE.

[10] R. Salman, "Developing Multithreaded Database Application Using Java Tools and Oracle Database Management System in Intranet Environment," International Conference on Advanced Information Technologies and Applications, pp. 67-79, 2015. 